\title{
Treatment of Candida infections with fluconazole in adult liver transplant recipients: Is TDM-guided dosing adaptation helpful?
}

\author{
Elda Righi ${ }^{1,2}$ (D) | Alessia Carnelutti ${ }^{1}$ | Umberto Baccarani ${ }^{3,4}$ | Assunta Sartor ${ }^{5}$ | \\ Piergiorgio Cojutti ${ }^{4,6}$ | Matteo Bassetti ${ }^{1,4}$ | Federico Pea ${ }^{4,6}$
}

${ }^{1}$ Infectious Diseases Division, Azienda Sanitaria Universitaria Integrata Santa Maria della Misericordia, Udine, Italy

${ }^{2}$ Infectious Diseases, Department of Diagnostics and Public Health, University of Verona, Verona, Italy

${ }^{3}$ General Surgery and Transplantation Unit, Azienda Sanitaria Universitaria Integrata Santa Maria della Misericordia, Udine, Italy

${ }^{4}$ Department of Medicine, University of Udine, Udine, Italy

${ }^{5}$ Microbiology Unit, Azienda Sanitaria Universitaria Integrata Santa Maria della Misericordia, Udine, Italy

${ }^{6}$ Institute of Clinical Pharmacology, Azienda Sanitaria Universitaria Integrata Santa Maria della Misericordia, Udine, Italy

\section{Correspondence}

Elda Righi, Infectious Diseases Division, Azienda Sanitaria Universitaria Integrata Santa Maria della Misericordia, 50, Colugna Street, Udine (UD) 33100, Italy.

Email: elda.righi@libero.it

\begin{abstract}
Background: Fluconazole represents a common antifungal option for the treatment of Candida infections in liver transplant recipients. Although adequate antifungal exposure is known to correlate with favorable outcomes in patients with invasive candidiasis, therapeutic drug monitoring (TDM) of fluconazole is currently not recommended.

Methods: We conducted a retrospective study including adult liver transplant recipients receiving fluconazole for invasive candidiasis and undergoing TDM. We assessed the correlation between clinical variables, fluconazole trough plasma levels $\left(\mathrm{C}_{\min }\right)$, and outcome.
\end{abstract}

Results: Twenty-seven patients (74\% males; median age 57 years) were included. Abdominal candidiasis was the most frequent infection (56\%). Median duration of fluconazole therapy was 17 days (IQR 9-21). Fluconazole median $C_{\min }$ was $11.0 \mathrm{mg} / \mathrm{L}$ (range 2.4-30.6 mg/L). Five (19\%) patients required TDM-guided fluconazole dose increase. All-cause in hospital mortality was $33 \%$. Fluconazole $C_{\min }>11 \mathrm{mg} / \mathrm{L}$ significantly correlated with clinical success (OR 8.78, 95\% Cl 1.13-67.8, $P=0.04$ ).

Conclusions: Our study identified decreased fluconazole $\mathrm{C}_{\min }$ as a factor associated with negative outcomes in liver transplant recipients with Candida infection. TDM of fluconazole may be advisable in this patient population.

\section{KEYWORDS}

fluconazole, invasive candidiasis, liver transplant recipients, outcome, therapeutic drug monitoring

\section{1 | INTRODUCTION}

Liver transplant recipients (LTR) have an increased risk of developing invasive candidiasis (IC), a life-threatening infection associated with mortality rates up to $70 \% .{ }^{1-3}$ Prompt administration of adequate antifungal treatment has demonstrated to improve the outcome of patients with IC. ${ }^{4,5}$ The choice of the most appropriate antifungal agent in LTR depends on various factors, including patient's pathophysiology, disease severity, and Candida species. ${ }^{3}$ Recent guidelines 
creatinine clearance $(\mathrm{CrCl})$ estimated values might result in inappropriate exposure due to the poor performance that $\mathrm{CrCl}$ formulas may have in predicting glomerular filtration rate in this population. ${ }^{11,12}$ For this reason, since several years our institution performs TDM of fluconazole in LTR with the intent of individualizing drug exposure.

Aim of the study was to analyze the clinical characteristics and the factors associated with fluconazole trough levels $\left(C_{\text {min }}\right)$ in a cohort of LTR treated for confirmed or suspected Candida infections.

\section{2 | METHODS}

\section{1 | Study population}

A retrospective, observational study was conducted at a 1100-bed tertiary care university hospital performing liver transplants since 2004. Adult (aged 18 and older) orthotopic LTR undergoing at least one determination of fluconazole $\mathrm{C}_{\min }$ during the period August 2009-August 2016 were included. Only the first episode treated with fluconazole was considered for each patient. Fluconazole was administered for proven or suspected fungal infection due to Candida spp. Proven infection was defined as recovery of Candida spp from a normally sterile site in presence of signs and symptoms of infection, as previously reported. ${ }^{13}$ Suspected candidiasis was based on clinicians' judgment in presence of risk factors for Candida infection along with clinical, radiological, or laboratory evidence consistent with an infectious disease process. Identification of isolates and antimicrobial susceptibility profiles were performed as previously described. ${ }^{14}$ Patients' demographics, timing from liver transplant, site of infection, type of Candida strain, fluconazole dosage, fluconazole $\mathrm{C}_{\text {min }}$, and outcome were collected through electronic databases. Changes in liver enzymes and kidney function during fluconazole treatment were also recorded. Clinical success during fluconazole treatment was defined as cure or significant improvement of signs and symptoms of infection along with microbiological success, defined as eradication if follow-up culture results were negative for Candida, or presumed eradication if follow-up blood cultures were not available but the clinical outcome was defined as success. Failure of response was defined as no significant improvement in signs and symptoms, death, or positive follow-up blood culture results. In-hospital mortality was defined as death during hospitalization in which fluconazole treatment and TDM were performed.

The local institutional review board approved the study, and written patient consent was waived because of the retrospective nature of the study.

\subsection{Fluconazole treatment and TDM}

According to the Summary of Product Characteristics, fluconazole daily dose up to $400 \mathrm{mg} / \mathrm{d}$ is suggested for the treatment of IC in adult patients. ${ }^{15}$ In presence of impaired renal function $(\mathrm{CrCl}$ $<50 \mathrm{~mL} / \mathrm{min}$ ) dose reduction of $50 \%$ is recommended. ${ }^{15}$ Fluconazole initial dosage was based on the treating physician's judgment and subsequently adjusted according to real-time TDM.
Since many years fluconazole TDM is performed at our institution by means of a validated HPLC technique and is available for all hospitalized patients receiving fluconazole upon request of the treating physician. ${ }^{16}$ Since 2009 , fluconazole levels are routinely detected and electronically recorded among LTR receiving fluconazole through monitoring of $C_{\min }$ and peak plasma levels. Based on the results of TDM, dose adjustments for LTR were recommended by an experienced clinical pharmacologist with the purpose of maintaining $C_{\min }$ close to $10 \mathrm{mg} / \mathrm{L}$. A dose increase was suggested for fluconazole concentrations below the desired level $\left(C_{\min }<8 \mathrm{mg} / \mathrm{L}\right)$. Conversely, fluconazole dose was usually reduced when $C_{\min }$ was more than twice the target level. Subsequent $C_{\min }$ assessments following dose adjustments were performed in order to confirm the achievement of target $\mathrm{C}_{\text {min }}$.

This approach is finalized to achieve the pharmacodynamics target of efficacy, defined as an area under the concentration-time curve/MIC (AUC/MIC) ratio >100 against all fluconazole-susceptible strains of Candida (MIC $\leq 2 \mathrm{mg} / \mathrm{L}$, with MIC tested according to EUCAST methodology). ${ }^{17,18}$ Fluconazole $C_{\min }$ were assessed at steady state after at least 3-5 days of treatment.

\section{3 | Statistical analysis}

Continuous and categorical data were reported as mean \pm SEM or median (25th and 75th percentile) and frequency distributions, respectively. Categorical variables were evaluated using chi-square or, when appropriate, the two-tailed Fisher's exact test. To determine correlations between two continuous variables, a Spearman correlation coefficient was calculated. Mann-Whitney $U$ test was used for comparing two groups. Logistic regression analysis was used to identify the variables correlated to clinical success among LTR with Candida infection. Variables with statistically significant association on univariate analysis were included in a multivariable binary logistic regression model. The area under the receiver-operating characteristic (ROC) curve and Youden's Index were calculated to established cut-off values for the variables with highest sensitivity and specificity for clinical success. Analyses were performed using SPSS v. 20.0 (IBM, SPSS). All tests were two-tailed, and a $P$ value $>0.05$ was determined to represent statistical significance.

\section{3 | RESULTS}

A total of 27 liver transplant recipients (LTR) underwent at least one fluconazole TDM during the study period. Patients' characteristics are summarized in Table 1. Twenty (74\%) patients were males and 7 (26\%) females. Median age was 57 years (IQR 52.0-60.3). Conditions leading to liver transplant included HCV-related cirrhosis, (12/27, $44 \%)$ alcoholic liver cirrhosis (8/27, 30\%), HBV-related cirrhosis $(4 / 27,15 \%)$, primary biliary cirrhosis $(2 / 27,7 \%)$, and fulminant hepatitis B (1/27, 4\%). Concomitant HCC was detected in 10 cases (37\%). Median MELD score at transplantation was 17.5 (IQR 14.0-23.3) with $50 \%$ of patients presenting with Child's B disease. Risk factors 
TAB LE 1 Characteristics of liver transplant recipients included in the study $(n=27)$

\begin{tabular}{|c|c|}
\hline Characteristic & $N=27$ \\
\hline Age (y, IQR) & $57(52.0-60.3)$ \\
\hline Males (\%) & $20(74)$ \\
\hline \multicolumn{2}{|l|}{ Reason for liver transplantation (\%) } \\
\hline HCV-related cirrhosis & $7(26)$ \\
\hline $\mathrm{HCV}+\mathrm{HCC}$ & $3(11)$ \\
\hline $\mathrm{HIV} / \mathrm{HCV}+\mathrm{HCC}$ & $2(7)$ \\
\hline HBV-related cirrhosis & $2(7)$ \\
\hline $\mathrm{HBV}+\mathrm{HCC}$ & $3(11)$ \\
\hline Alcohol-related & $5(19)$ \\
\hline Alcohol + HCC & $2(7)$ \\
\hline Primary biliary cirrhosis & $2(7)$ \\
\hline Fulminant HBV & $1(4)$ \\
\hline Charlson comorbidity score (IQR) & $3.3(2.0-4.5)$ \\
\hline \multicolumn{2}{|l|}{ Renal impairment (\%) } \\
\hline Mild (CrCl 50-80 mL/min) & $13(48)$ \\
\hline Moderate (CrCl 31-49 mL/min) & $7(26)$ \\
\hline Severe $(\mathrm{CrCl} 10-30 \mathrm{~mL} / \mathrm{min})$ & $4(15)$ \\
\hline Albumin g/L (IQR) & $25.7(19.0-30.3)$ \\
\hline Creatinine mg/dL (IQR) & $1.20(0.98-1.69)$ \\
\hline BMI $\left(\mathrm{kg} / \mathrm{m}^{2}\right)$ & $22.9(20.6-26.9)$ \\
\hline \multicolumn{2}{|l|}{ Site of infection (\%) } \\
\hline Intra-abdominal & $15(56)$ \\
\hline Biliary & $8(30)$ \\
\hline BSI & $3(10)$ \\
\hline Esophageal & $1(4)$ \\
\hline Candida species (\%) & $19(70)$ \\
\hline Calbicans & $11 / 19(58)$ \\
\hline Cglabrata & 4/19 (21) \\
\hline Cparapsilosis & $2 / 19(11)$ \\
\hline C tropicalis & $1 / 19(5)$ \\
\hline Mixed (C albicans and glabrata) & $1 / 19(5)$ \\
\hline Timing from LT (d, IQR) & $42(10-406)$ \\
\hline $\begin{array}{l}\text { Median duration of hospitalization (d, } \\
\text { IQR) }\end{array}$ & $45(29-62)$ \\
\hline MELD score & $17.5(14.0-23.5)$ \\
\hline Hospitalization in ICU (\%) & $8(33)$ \\
\hline Concomitant antimicrobial therapy (\%) & $18(67)$ \\
\hline Fever (\%) & $12(44)$ \\
\hline $\begin{array}{l}\text { Concomitant documented bacterial infec- } \\
\text { tions (\%) }\end{array}$ & $12(44)$ \\
\hline \multicolumn{2}{|l|}{ Type } \\
\hline BSI & $7 / 12(58)$ \\
\hline Abdominal & $5 / 12(42)$ \\
\hline \multicolumn{2}{|l|}{ Pathogen } \\
\hline Enterococcus spp & $6 / 12(50)$ \\
\hline
\end{tabular}

(Continues)
TABLE 1 (Continued)

\begin{tabular}{|cc|}
\hline Characteristic & $\mathrm{N}=27$ \\
\hline \multicolumn{1}{|c|}{ Enterobacteriaceae } & $4 / 12(33)$ \\
\hline Other & $2 / 12(17)$ \\
\hline Fluconazole treatment duration (d, IQR) & $17(9-21)$ \\
\hline Concomitant immunosuppressive therapy (\%) \\
\hline Tacrolimus & $17(63)$ \\
\hline Cyclosporin A & $8(30)$ \\
\hline Everolimus & $2(7)$ \\
\hline
\end{tabular}

Note: Results are expressed as percentage (\%) or median and interquartile range (IQR).

Abbreviations: $\mathrm{BSI}$, bloodstream infection; $\mathrm{CrCl}$, creatinine clearance; HCC, hepatocellular carcinoma; HCV, hepatitis C virus; LT, liver transplant.

associated with development of IC included the use of broad-spectrum antibiotics within 30 days prior of the start of fluconazole (24/27, 89\%), recent (<6 months) abdominal or biliary tract surgery (14/27, 52\%), severe renal impairment (4/27, 15\%), and concomitant CMV reactivation (3/27, 11\%). Candida infection was microbiologically confirmed in 19 (70\%) cases, and C albicans represented the most frequently isolated species (58\%). All strains were reported as susceptible to fluconazole. Intra-abdominal infections accounted for $56 \%$ of infections (three peritonitis and 12 abdominal collection), followed by cholangitis $(8 / 27,30 \%)$, bloodstream infections $(3 / 27$, $11 \%)$, and esophagitis $(1 / 27,4 \%)$. Concomitant bacterial infections were reported in 12 (44\%) patients.

Median time from transplantation to the initiation of fluconazole treatment was 42 days (IQR 10-406). Median duration of fluconazole therapy was 17 days (IQR 9-21). All patients received intravenous fluconazole. Overall, median maintenance dose of fluconazole (after an initial loading dose between 800 and $200 \mathrm{mg}$ ) ranged from 2.7 to $7.27 \mathrm{mg} / \mathrm{kg} / \mathrm{d}$. Fluconazole was dosed according to the Summary of Product Characteristics (SPC) in 24 patients (85\%), while 4 (15\%) patients with normal renal function received an initial dose below $6 \mathrm{mg} / \mathrm{Kg} / \mathrm{d}$ according to the treating physician's judgment. All patients received concomitant immunosuppressive therapy.

Fluconazole $\mathrm{C}_{\min }$ ranged from 2.4 to $30.6 \mathrm{mg} / \mathrm{L}$. Median fluconazole $C_{\text {min }}$ was $11.0(7.9 ; 15.6) \mathrm{mg} / \mathrm{L}$ at first TDM and $11.6 \mathrm{mg} / \mathrm{L}$ (8.1; 16.6) after TDM-guided dosage adjustments. Overall, 18 (67\%) patients achieved fluconazole $C_{\min }$ above $10 \mathrm{mg} / \mathrm{L}$ during treatment and 15 (56\%) of these had $C_{\text {min }}>11 \mathrm{mg} / \mathrm{L}$. Five out of 27 (19\%) patients did not achieve fluconazole $\mathrm{C}_{\min }>8 \mathrm{mg} / \mathrm{L}$ in the first determination and required dose increase. After dose adjustments, fluconazole $\mathrm{C}_{\min }>8 \mathrm{mg} / \mathrm{L}$ was achieved in 25 (93\%) patients. Two patients did not achieve concentrations $>8 \mathrm{mg} / \mathrm{L}$ during treatment: one was an HIVpositive patient receiving fluconazole for esophageal candidiasis and one was a patient hospitalized in ICU with candidemia receiving fluconazole doses up to $500 \mathrm{mg} / \mathrm{d}$. Median fluconazole dose (initial or after dose adjustment) resulting in $\mathrm{C}_{\text {min }}$ concentration $>8 \mathrm{mg} / \mathrm{L}$ was $4.2 \mathrm{mg} / \mathrm{kg} / \mathrm{d}$ (IQR, 3.5-5.8). The four patients receiving reduced 
fluconazole doses had median $\mathrm{C}_{\min }$ of $8.83 \mathrm{mg} / \mathrm{L}$ (IQR 4.8-10.5) at steady state and all reached $\mathrm{C}_{\text {min }}>9 \mathrm{mg} / \mathrm{L}$ during treatment. No changes in $\mathrm{CrCl}$ or liver enzymes were detected during fluconazole treatment. In 12 (44\%) patients with high fluconazole $\mathrm{C}_{\text {min }}$ (more than twice the target level), dose reduction was performed and fluconazole $\mathrm{C}_{\text {min }}$ maintained $>10 \mathrm{mg} / \mathrm{L}$.

Fluconazole dose significantly correlated with $C_{\min }(r s=0.560$, $P=0.002$ ), while other parameters such as age, albuminemia, BMI, and $\mathrm{CrCl}$ did not appear significantly associated with fluconazole levels (Table S1).

Table 2 compares fluconazole $\mathrm{C}_{\min }$ in different patient groups. Although decreased levels of fluconazole were documented for patients with low albuminemia (<20 g/L) and high BMI ( $>25)$, the univariate analysis did not show significant influence of demographic or laboratory parameters on fluconazole $\mathrm{C}_{\min }$.

Dosing adaptation of concomitant immunosuppressive therapy was required in $17 / 27(63 \%)$ patients: $11 / 17(65 \%)$ receiving tacrolimus (TAC), 5/8 (63\%) receiving cyclosporine A (CsA), and 1/2 (50\%) treated with everolimus (EVR). Mean percentage dose reduction was $42 \%$ for TAC, 36\% for CsA, and 13\% for EVR.

In five cases (three BSI and two biliary infections), microbiological cultures were available at the end of antifungal treatment, and all documented Candida eradication. Median fluconazole $C_{\text {min }}$ among patients with microbiological eradication was $10.7 \mathrm{mg} / \mathrm{L}$ (IQR 8.3-15.5). Eight (30\%) patients were admitted in the ICU and $3(11 \%)$ patients presented with sepsis. None of the patients received renal replacement therapy or treatment with extracorporeal membrane oxygenation (ECMO) while receiving fluconazole.

Recurrent Candida biliary or abdominal infections within 3 months from the previous episode were reported in 2 (7\%) patients. Switch of antifungal treatment from fluconazole to caspofungin or voriconazole was performed in 4/27 (15\%) cases (three patients with $C$ glabrata and one with $C$ parapsilosis infection) due to worsening conditions. Overall all-cause in-hospital mortality was 9/27 (33\%). Median time from fluconazole therapy initiation and death was 44 days (IQR 32-80). In 4/9 (44\%) cases, mortality appeared related to the presence of candidiasis.

Mortality was significantly higher among patients with lower fluconazole $C_{\min }$ either at first TDM (8.5 mg/L, IQR 5.7-10.7 and $12.7 \mathrm{mg} / \mathrm{L}$, IQR 8.9-20.2, $P=0.02$ ) or at subsequent occurrences (10.4 mg/L, IQR 7.10-11.1 and 15.1 mg/L, IQR 8.9-21.1, $P=0.03$; Figure S1). Univariate analysis showed that mortality was significantly higher among patients with decreased serum albumin levels $(P=0.04)$ and those hospitalized in the ICU $(P=0.01)$ (Table 3). Although mortality was higher for fluconazole $\mathrm{MIC}>1 \mathrm{mg} / \mathrm{L}$ vs $\mathrm{MIC} \leq 1 \mathrm{mg} / \mathrm{L}$ ( $50 \%$ vs $22 \%$, respectively, $P=0.52$ ), the difference was not statistically significant.

Clinical success was documented in 15 (56\%) patients. Univariate analysis identified serum albumin $>20 \mathrm{~g} / \mathrm{L}$ and fluconazole $\mathrm{C}_{\min }$ $>11 \mathrm{mg} / \mathrm{L}$ as factors associated with clinical success (Table 4). Multivariate analysis showed that only $C_{\min }>11 \mathrm{mg} / \mathrm{L}$ was an independent factor significantly associated with clinical success (OR 8.78, 95\% Cl 1.13-67.8, $P=0.04$ ).
Areas under the receiver-operating characteristic (ROC) curve showed that fluconazole $C_{\min }>11 \mathrm{mg} / \mathrm{L}$ had highest sensitivity, specificity, and Youden's Index in predicting clinical success (Table S2 and Figure S2).

\section{4 | DISCUSSION}

As previously reported, we observed high (>30\%) in hospital mortality in LTR with Candida infections. ${ }^{1,19}$ The intrabdominal site was also confirmed to be a common site for candidiasis among LTR. ${ }^{14}$ Fluconazole still represents the drug of choice in the treatment of candidiasis for patients who are clinically stable and did not report recent exposure to azoles. ${ }^{6,7,20}$ Furthermore, the role of fluconazole in deep-seated infections is supported by its excellent tissue penetration. ${ }^{21}$ We previously showed that intra-abdominal penetration of fluconazole was very high in three LTR with intra-abdominal candidiasis (eg, two cases of cholangitis and one of peritonitis), ranging from $50 \%$ to $85 \% .{ }^{16}$ In the same study, TDM-guided fluconazole therapy was performed with maintenance of plasma $\mathrm{C}_{\min }$ at around $15 \mathrm{mg} / \mathrm{L}$ for 14 days, resulting in clinical resolution of the infection. ${ }^{16}$

TDM of fluconazole is generally not recommended due to its approximately linear and predictable PK behavior, so that dosing adaptations based on $\mathrm{CrCl}$ estimates are considered appropriate in clinical practice. ${ }^{10}$ However, it should not be overlooked that in LTR the reliability of $\mathrm{CrCl}$ in predicting renal function was shown to be poor. ${ }^{11}$ Fluconazole TDM-guided dosing adjustments may be advisable in this population since adaptation based only on $\mathrm{CrCl}$ estimates could result in inaccurate fluconazole exposure. We also confirmed that in LTR low fluconazole maintenance dosages (100-200 mg daily) appeared sufficient to achieve optimal probability of target attainment against $C$ albicans. ${ }^{12,16}$

Liver toxicity associated with fluconazole use has been reported. ${ }^{15,22}$ No clear association between fluconazole concentrations and liver function, however, has been documented to justify fluconazole TDM for toxicity purposes. ${ }^{10}$ In our study, drug reduction was

TABLE 2 Fluconazole median $C_{\min }(\mathrm{mg} / \mathrm{L})$ in different patient groups

\begin{tabular}{|llll}
\hline Characteristic & Yes & No & $P$ value \\
\hline Male sex & $10.7(7.9 ; 13.4)$ & $12.8(6.3 ; 17.1)$ & 0.66 \\
\hline ICU admission & $11.0(6.3 ; 16.0)$ & $10.9(8.6 ; 19.2)$ & 0.83 \\
\hline $\begin{array}{c}\text { Serum albumin } \\
<20 \mathrm{~g} / \mathrm{L}\end{array}$ & $7.9(6.2 ; 10.5)$ & $12.4(8.9 ; 19.3)$ & 0.07 \\
\hline $\mathrm{CrCl}<50 \mathrm{~mL} / \mathrm{min}$ & $13.8(7.5 ; 22.4)$ & $11.0(7.4 ; 12.7)$ & 0.32 \\
\hline $\mathrm{BMI}>25$ & $7.9(6.2 ; 11.0)$ & $12.4(8.6 ; 19.3)$ & 0.60 \\
\hline $\mathrm{MELD}>15$ & $12.6(9.1 ; 17.6)$ & $9.6(6.2 ; 13.2)$ & 0.24 \\
\hline
\end{tabular}

Note: Median fluconazole $\mathrm{C}_{\min }$ reported in the table were measured at first therapeutic drug monitoring; target of $C_{\min }$ was $10 \mathrm{mg} / \mathrm{L}$, with dose increase recommended for $\mathrm{C}_{\min }<8 \mathrm{mg} / \mathrm{L}$. Results are expressed as median and interquartile range (IQR) of fluconazole median $\mathrm{C}_{\min }(\mathrm{mg} / \mathrm{L})$. Abbreviations: BMI, body mass index; ICU, intensive care unit; MELD, model for end stage liver disease. 
suggested for high fluconazole $\mathrm{C}_{\min }$ (eg, more than twice the target level) in order to maintain a concentration target around $10 \mathrm{mg} / \mathrm{L}$. In our study, fluconazole $C_{\min }$ up to $31 \mathrm{mg} / \mathrm{L}$ were not associated with changes in liver or renal function during treatment.

TAB LE 3 Univariate analysis of factors associated with inhospital mortality

\begin{tabular}{|c|c|c|c|}
\hline Factor & Lived (18) & Died (9) & $\begin{array}{l}P \\
\text { value }\end{array}$ \\
\hline Male sex (\%) & $13(87)$ & $7(78)$ & 1.00 \\
\hline Age (y, IQR) & $54.0(51.8-59.0)$ & $60.0(54.0-62.5)$ & 0.32 \\
\hline Charlson score (IQR) & $4.0(2.8-5.0)$ & $3.0(2.0-3.8)$ & 0.08 \\
\hline $\mathrm{BMI}, \mathrm{kg} / \mathrm{m}^{2}$ (IQR) & $22.3(20.6-23.9)$ & $26.8(22.0-28.0)$ & 0.08 \\
\hline Time from $L T(d, I Q R)$ & $160(14.0-432.0)$ & $40(3.0-137.5)$ & 0.11 \\
\hline $\begin{array}{l}\text { Serum albumin, } \mathrm{g} / \mathrm{L} \\
\text { (IQR) }\end{array}$ & $26.3(23.8-31.2)$ & $19.0(16.0-25.3)$ & 0.04 \\
\hline $\mathrm{CrCl}, \mathrm{ml} / \mathrm{min}(\mathrm{IQR})$ & 57.9 (39.3-68.3) & $73.6(49.7-88.2)$ & 0.20 \\
\hline $\begin{array}{l}\text { Concomitant bacte- } \\
\text { rial infection (\%) }\end{array}$ & $7(47)$ & $5(56)$ & 0.68 \\
\hline $\begin{array}{l}\text { Concomitant bacte- } \\
\text { rial BSI (\%) }\end{array}$ & $4(27)$ & $3(33)$ & 0.65 \\
\hline $\begin{array}{l}\text { Non albicans Candida } \\
\text { (\%) }\end{array}$ & 4/12 (33) & $4 / 6(67)$ & 0.31 \\
\hline $\begin{array}{l}\text { Median MELD score } \\
\text { (IQR) }\end{array}$ & $14.5(10.0-18.0)$ & $17.0(15.0-20.0)$ & 0.10 \\
\hline $\begin{array}{l}{ }^{a} \text { Mean fluconazole } \\
\mathrm{C}_{\min }, \mathrm{mg} / \mathrm{L}(\mathrm{IQR})\end{array}$ & $12.7(8.9-20.2)$ & $8.5(5.7-10.7)$ & 0.02 \\
\hline ICU stay (\%) & $2(13)$ & $6(67)$ & 0.01 \\
\hline $\begin{array}{l}\text { Median hospital stay } \\
\text { (d, IQR) }\end{array}$ & $33.0(21.8-55.5)$ & $62.0(47.0-134.5)$ & 0.07 \\
\hline
\end{tabular}

Note: Results are expressed as percentage (\%) or median and interquartile range (IQR).

Abbreviations: $\mathrm{BMI}$, body mass index; $\mathrm{BSI}$, bloodstream infections; $\mathrm{CrCl}$, creatinine clearance; ICU, intensive care unit; LT, liver transplant; MELD, model for end stage liver disease.

${ }^{a}$ Measured at first therapeutic drug monitoring. Statistically significant values are shown in bold.
The PK/PD parameter that best predicts the outcome for fluconazole is the AUC/MIC ratio. ${ }^{23,24}$ AUC/MIC ratios $\geq 55.2$ were generally associated with favorable clinical outcomes, ${ }^{16}$ but higher target values $(>100)$ have been advocated for certain categories of patients, such as pediatric and critically ill patients, especially those receiving hemofiltration. ${ }^{10,25,26}$ Our fluconazole $C_{\min }$ target was set at around $10 \mathrm{mg} / \mathrm{L}$. Although rough, the approach of targeting $\mathrm{C}_{\mathrm{min}}$ at this value is in line with the intent of achieving AUC/MIC ratio of at least 100 against all of the fluconazole-susceptible (EUCAST clinical breakpoint $2 \mathrm{mg} / \mathrm{L}$ ) strains of Candida spp [10 mg/L $\times 24 \mathrm{~h}$ ours) $/ 2 \mathrm{mg} / \mathrm{L}=120]$. A previous study including pediatric patients receiving fluconazole showed increased microbiological eradication rates for fluconazole $C_{\min }>11 \mathrm{mg} / \mathrm{L} .{ }^{9}$ Although we could not confirm a positive impact of $C_{\min }$ on Candida eradication due to the limited number of patients with repeated microbiological cultures, we observed that comparable cut-off value $\left(C_{\min }>11 \mathrm{mg} / \mathrm{L}\right)$ were associated with clinical success in our study. Although decreased $\mathrm{C}_{\min }$ were more common among patients with Candida infection who died during hospitalization compared to survivors, the small sample size and potential confounding factors prevented us from drawing conclusions about the impact of fluconazole concentrations on mortality. Finally, although increased fluconazole MICs appeared correlated with higher mortality rates, this result was not statistically significant, probably because of the limited number of patients enrolled in the study.

Univariate analysis showed that hypoalbuminemia appeared associated with poor outcomes. No significant correlations, however, were shown between fluconazole $\mathrm{C}_{\min }$ and albumin serum levels in our cohort. As previously reported, the unbound fraction of fluconazole should not be affected by hypoalbuminemia since only a small moiety (12\%) of fluconazole molecules is bound to plasma protein. ${ }^{27}$ Hypoalbuminemia, however, has been linked with increased mortality among patients on liver transplant waiting list. ${ }^{28,29}$ There is currently no consensus to support albumin supplementation in this patient population. ${ }^{30,31}$

In conclusion, the findings of a statistically significant association between fluconazole $C_{\min }>11 \mathrm{mg} / \mathrm{L}$ and clinical success appear
TAB LE 4 Univariate and multivariate analysis of factors associated with clinical success

\begin{tabular}{|c|c|c|c|c|}
\hline \multirow[b]{2}{*}{ Characteristic } & \multicolumn{2}{|l|}{ Univariate analysis } & \multicolumn{2}{|l|}{ Multivariate analysis } \\
\hline & OR $(95 \%$ IC) & $P$ value & OR (95\% IC) & $P$ value \\
\hline Age $<60$ y & $0.80(0.16-4.02)$ & 0.78 & & \\
\hline Charlson score $<4$ & $1.36(0.28-6.58)$ & 0.70 & & \\
\hline $\begin{array}{l}\text { Mean } \mathrm{CrCl}>50 \mathrm{~mL} / \\
\min \end{array}$ & $0.63(0.12-3.32)$ & 0.58 & & \\
\hline $\begin{array}{l}{ }^{\text {a} F l u c o n a z o l e ~} \mathrm{C}_{\min } \\
>11 \mathrm{mg} / \mathrm{L}\end{array}$ & $13.0(1.92-87.99)$ & 0.01 & $8.76(1.13-67.77)$ & 0.04 \\
\hline No ICU stay & $0.35(0.06-1.93)$ & 0.23 & & \\
\hline $\begin{array}{l}\text { Albuminemia } \\
>20 \mathrm{~g} / \mathrm{L}\end{array}$ & 14.0 (1.37-142.89) & 0.03 & $8.31(0.66-104.26)$ & 0.10 \\
\hline
\end{tabular}

Note: Variables with statistically significant association on univariate analysis (fluconazole $\mathrm{C}_{\min }$, albuminemia) were included in a multivariable binary logistic regression model.

Abbreviations: $\mathrm{CrCl}$, creatinine clearance; ICU, intensive care unit.

${ }^{a}$ Measured at first therapeutic drug monitoring. Statistically significant values are shown in bold. 
to support our choice of performing TDM in LTR with candidiasis, although the results should be interpreted with caution due to the limited number of patients enrolled in the study. To the best of our knowledge, however, this is the first study analyzing the potential role of fluconazole TDM in improving clinical outcomes of liver transplant recipients with candidiasis.

Our study has several limitations. Firstly, due to the retrospective nature of the study and the site of Candida infections, that was abdominal in the majority of cases, a systematic assessment of the microbiological resolution of the infection was unfeasible. Secondly, the analysis of the association between fluconazole levels and outcome among severely ill (eg, ICU admitted) patients or patients with non albicans candidiasis was unfeasible due to the limited sample size. Thirdly, the retrospective nature of the study limits the generalizability of the findings, considering that other factors other than Candida infection could have been implicated in patients' outcome. This, however, represents a common limitation in studies assessing the outcome of patients with invasive candidiasis that is often affected by multiple confounders such as patients' complexity and multiple comorbidities. Finally, we recognize that TDM based only on $C_{\min }$ determination is a rough measurement and did not allow an appropriate estimation of AUC, potentially causing underestimation of drug exposure.

In conclusion, our study suggests that TDM of fluconazole $C_{\min }$ may be advisable in LT recipients with suspected or documented candidiasis. Prospective studies in larger cohorts are warranted to confirm the utility of TDM in LTR and to further analyze the correlation between fluconazole exposure and clinical outcome.

\section{ACKNOWLEDGEMENTS}

None.

\section{CONFLICT OF INTEREST}

The authors have no conflict of interest.

\section{AUTHOR CONTRIBUTION}

ER and FP designed the study, collected and analyzed the data, and wrote the manuscript; AC, UB, AS, PC, MB contributed to laboratory and clinical data collection and to the critical revision of the manuscript.

\section{ORCID}

Elda Righi (iD https://orcid.org/0000-0001-8718-1200

\section{REFERENCES}

1. Andes DR, Safdar N, Baddley JW, et al. The epidemiology and outcomes of invasive Candida infections among organ transplant recipients in the United States: results of the transplant-associated infection surveillance network (TRANSNET). Transpl Infect Dis. 2016;18:921-931.

2. Neofytos D, Fishman JA, Horn D, et al. Epidemiology and outcome of invasive fungal infections in solid organ transplant recipients. Transpl Infect Dis. 2010;12:220-229.

3. Gavaldà J, Meije Y, Fortún J, et al. Invasive fungal infections in solid organ transplant recipients. Clin Microbiol Infect. 2014;20(suppl 7):27-48.

4. Patel GP, Simon D, Scheetz M, Crank CW, Lodise T, Patel N. The effect of time to antifungal therapy on mortality in Candidemia associated septic shock. Am J Ther. 2009;16:508-511.

5. Kollef M, Micek S, Hampton N, Doherty JA, Kumar A. Septic shock attributed to Candida infection: importance of empiric therapy and source control. Clin Infect Dis. 2012;54:1739-1746.

6. Pappas PG, Kauffman CA, Andes DR, et al. Clinical practice guideline for the management of candidiasis: 2016 update by the infectious diseases society of America. Clin Infect Dis. 2016;62:e1-50.

7. Cornely OA, Bassetti M, Calandra T, et al. ESCMID guideline for the diagnosis and management of Candida diseases 2012: non-neutropenic adult patients. Clin Microbiol Infect. 2012;18(Suppl 7):19-37.

8. Laverdiere M, Bow JE, Rotstein C, et al. Therapeutic drug monitoring for triazoles: a needs assessment review and recommendations from a Canadian perspective. Can J Infect Dis Med Microbiol. 2014; 25:327-343.

9. Van der Elst KC, Pereboom M, van den Heuvel ER, Kosterink JG, Schölvinck EH, Alffenaar JW. Insufficient fluconazole exposure in pediatric cancer patients and the need for therapeutic drug monitoring in critically ill children. Clin Infect Dis. 2014;59:1527-1533.

10. Ashbee HR, Barnes RA, Johnson EM, Richardson MD, Gorton R, Hope WW. Therapeutic drug monitoring (TDM) of antifungal agents: guidelines from the British society for medical mycology. $J$ Antimicrob Chemother. 2014;69:1162-1176.

11. Cantarovich M, Yoshida EM, Peltekian KM, et al. Poor prediction of the glomerular filtration rate using current formulas in de novo liver transplant patients. Transplantation. 2006;82:433-436.

12. Cojutti PG, Lugano M, Righi E, et al. Population pharmacokinetics of fluconazole in liver transplantation: implications for target attainment for infections with Candida albicans and non-albicans spp. Eur J Clin Pharmacol. 2018;74(11): 1449-1459.

13. De Pauw B, Walsh T, Donnelly J, et al. Revised definitions of invasive fungal disease from the European organization for research and treatment of cancer/invasive fungal infections cooperative group and the national institute of allergy and infectious diseases mycoses study group (EORTC/MSG) consensus group. Clin Infect Dis. 2008;46:1813-1821.

14. Bassetti M, Peghin M, Carnelutti A, et al. Invasive Candida infections in liver transplant recipients: clinical features and risk factors for mortality. Transplant Direct. 2017;3(5):e156.

15. Fluconazole http://labeling.pfizer.com/ShowLabeling.aspx?xml:id=575\#Dosage. Accessed November 5, 2018.

16. Pea F, Righi E, Cojutti $P$, et al. Intra-abdominal penetration and pharmacodynamic exposure to fluconazole in three liver transplant patients with deep-seated candidiasis. J Antimicrob Chemother. 2014;69(9):2585-2586

17. Pai MP, Turpin RS, Garey KW. Association of fluconazole area under the concentration- time curve/MIC and dose/MIC ratios with mortality in nonneutropenic patients with candidemia. Antimicrob Agents Chemother. 2007;51:35-39.

18. Orasch C, Marchetti O, Garbino J, et al. Candida species distribution and antifungal susceptibility testing according to EUCAST and new vs. old CLSI clinical breakpoints: a six-year prospective candidemia survey from the Fungal Infection Network of Switzerland (FUNGINOS). Clin Microbiol Infect. 2014;20:698-705.

19. Raghuram A, Restrepo A, Safadjou S, et al. Invasive fungal infections following liver transplantation: incidence, risk factors, survival, and 
impact of fluconazole-resistant Candida parapsilosis (2003-2007). Liver Transpl. 2012;18:1100-1109.

20. Bassetti M, Marchetti M, Chakrabarti A, et al. A research agenda on the management of intra-abdominal candidiasis: results from a consensus of multinational experts. Intensive Care Med. 2013;39:2092-2106.

21. Felton T, Troke PF, Hope WW. Tissue penetration of antifungal agents. Clin Microbiol Rev. 2014;27:68-88.

22. Wang JL, Chang $\mathrm{CH}$, Young- $\mathrm{Xu} \mathrm{Y}$, Chan KA. Systematic review and meta-analysis of the tolerability and hepatotoxicity of antifungals in empirical and definitive therapy for invasive fungal infection. Antimicrob Agents Chemother. 2010;54:2409-2419.

23. Louie A, Drusano GL, Banerjee P, et al. Pharmacodynamics of fluconazole in a murine model of systemic candidiasis. Antimicrob Agents Chemother. 1998;42:1105-1109.

24. Andes D, van Ogtrop M. Characterization and quantitation of the pharmacodynamics of fluconazole in a neutropenic murine disseminated candidiasis infection model. Antimicrob Agents Chemother. 1999;43:2116-2120.

25. Clancy CJ, Yu VL, Morris AJ, Snydman DR, Nguyen MH. Fluconazole MIC and the fluconazole dose/MIC ratio correlate with therapeutic response among patients with candidemia. Antimicrob Agents Chemother. 2005;49:3171-3177.

26. Wade KC, Wu D, Kaufman DA, et al. Population pharmacokinetics of fluconazole in young infants. Antimicrob Agents Chemother. 2008;52:4043-4049.

27. Ulldemolins M, Roberts JA, Rello J, Paterson DL, Lipman J. The effects of hypoalbuminaemia on optimizing antibacterial dosing in critically ill patients. Clin Pharmacokinet. 1011;50:99-110.
28. Porrett PM, Baranov E, ter Horst M. Serum hypoalbuminemia predicts late mortality on the liver transplant waiting list. Transplantation. 2015;99(1):158-163.

29. Ahn J, Sundaram V, Ayoub WS, Frenette C, Wong RJ. Hypoalbuminemia is associated with significantly higher liver transplant waitlist mortality and lower probability of receiving liver transplant. J Clin Gastroenterol. 2018;52(10):913-917.

30. Ertmer C, Kampmeier T-G, Volkert T, et al. Impact of human albumin infusion on organ function in orthotopic liver transplantation-a retrospective matched-pair analysis. Clin Transplant. 2015;29(1):67-75.

31. Mukhtar A, EL Masry A, Moniem AA, Metini M, Fayez A, Khater YH. The impact of maintaining normal serum albumin level following living related liver transplantation: does serum albumin level affect the course? A Pilot Study. Transplant Proc. 2007;39(10):3214-3218.

\section{SUPPORTING INFORMATION}

Additional supporting information may be found online in the Supporting Information section at the end of the article.

How to cite this article: Righi E, Carnelutti A, Baccarani U, et al. Treatment of Candida infections with fluconazole in adult liver transplant recipients: Is TDM-guided dosing adaptation helpful? Transpl Infect Dis. 2019;21:e13113. https://doi. org/10.1111/tid.13113 